\title{
Research on STEAM Education in China under the Framework of Supply and Demand Theory
}

\author{
Chengzhe Zou \\ University of California, Davis, USA \\ czzou@ucdavis.edu
}

\begin{abstract}
This paper first explains the definition and historical evolution of STEAM education, which is different from the traditional Chinese education which focuses on the teaching of single subject book knowledge. STEAM education emphasizes the comprehensive application ability and creativity of disciplines, advocates the integration of subject knowledge in different fields, and forms the original scattered subject knowledge into a whole in practice, so that students can apply multiple disciplines in practice Knowledge solves problems. Then, this paper studies the current situation of STEAM education in China from the theoretical framework of supply and demand. On the demand side, the author analyzes the concept change of quality education driven by consumption upgrading, the demand for scientific and technological talents in the field of vocational education, and the enrichment of STEAM education products by technological progress. On the supply side, the author draws the upstream, midstream and downstream industry chain of STEAM education, and points out the problems existing in the industry, that is, the shortage of teachers, the serious homogenization of curriculum, and the high price limit the promotion of public schools. Finally, based on the above research, the author analyzes the future development trend of the industry, and believes that with the gradual improvement of social participation, the teaching scene will be more abundant, and the teaching mode will be more diversified, so as to provide suggestions and suggestions for the STEAM education industry practitioners.
\end{abstract}

\section{CCS CONCEPTS}

- KEYWORDS: STEAM Education; • Quality Education Reform; • Artificial Intelligence; • Mathematical Thinking;

\section{ACM Reference Format:}

Chengzhe Zou. 2021. Research on STEAM Education in China under the Framework of Supply and Demand Theory. In 2021 7th International Conference on Education and Training Technologies (ICETT 2021), April 14-16, 2021, Macau, China. ACM, New York, NY, USA, 8 pages. https://doi.org/10. $1145 / 3463531.3463554$

Permission to make digital or hard copies of all or part of this work for personal or classroom use is granted without fee provided that copies are not made or distributed for profit or commercial advantage and that copies bear this notice and the full citation on the first page. Copyrights for components of this work owned by others than ACM must be honored. Abstracting with credit is permitted. To copy otherwise, or republish, to post on servers or to redistribute to lists, requires prior specific permission and/or a fee. Request permissions from permissions@acm.org.

ICETT 2021, April 14-16, 2021, Macau, China

(C) 2021 Association for Computing Machinery.

ACM ISBN 978-1-4503-8966-2/21/04 ..\$15.00

https://doi.org/10.1145/3463531.3463554

\section{INTRODUCTION}

STEAM education originated in 1986. NSB published "undergraduate science, mathematics and engineering education" and come up with the concept of stem education for the first time, namely science, technology, engineering and mathematics. The main idea is to develop students' ability in science, technology, engineering, and mathematics. Since then, the U.S. government has incorporated "art" into the national education strategy, and stem education has evolved into STEAM education. The U.S. government attaches great importance to the development of STEAM education. It has promulgated a number of favorable policies such as "competitive excellence" and "ten-year plan for new science and technology education", and allocated special funds to promote the reform of STEAM education in the United States. At the same time, the American public strongly supports the development of STEAM education. Bill Gates, Zuckerberg and other well-known American entrepreneurs have participated in the American "programming hour" activities for many times, calling on the society to pay attention to programming skills, which provides a good development environment for STEAM education. With the rapid development of STEAM education in the United States, European countries also regard STEAM education as an significant part of national strategic development in the future, including the continuous improvement and improvement of the curriculum system and operation mechanism of "apprenticeship" education in the United Kingdom to solve the problem of shortage of STEAM skilled talents.

In terms of theoretical significance, (1) in terms of research content, the author finds that few studies focus on the topic from both supply and demand, while this paper analyzes STEAM education from a more comprehensive perspective and presents it with data and charts. (2) In terms of research methods, this paper uses literature review method, chart analysis method, data analysis method, case analysis method, country comparison method and other academic methods for analysis. In terms of practical significance, STEAM education has developed more mature in the European and American markets. Asian countries, such as Japan and South Korea, have also begun to promulgate policies to promote national STEAM education reform. At present, the penetration rate of STEAM education in South Korea is high, especially represented by roborobo, the largest robot training school and provider in South Korea. Its products include five series of building block robots, motor robots, aviation products and biological simulation products. It is the designated scientific and technological teaching aids for more than 1000 primary and secondary schools and kindergartens in South Korea. Compared with the developed countries in the world, the STEAM education industry in China started late, and there is still room for improvement in the curriculum system, teachers and social cognition. In 2013, STEAM education concept began to rise 


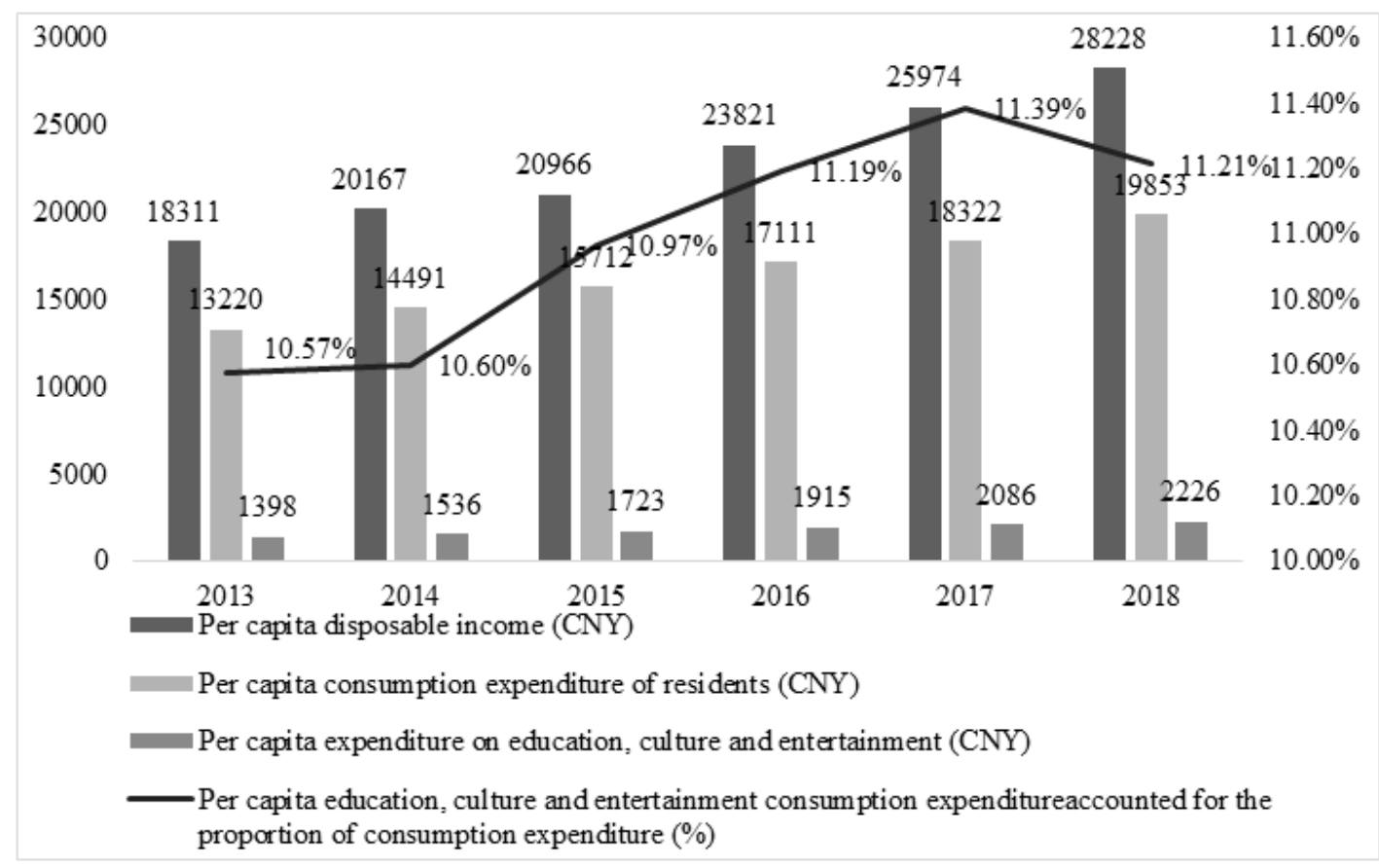

Figure 1: Per capita disposable income and expenditure of Chinese residents from 2013 to 2018 (CNY;\%)

in China, and a few off campus training institutions began to explore the application mode of STEAM education business in China, and developed curriculum system and teaching tools with Chinese characteristics on the basis of learning from the mature teaching mode of developed countries.

Since 2015, the Chinese government has continuously issued relevant policies to explicitly support the development of China's STEAM education industry, marking that STEAM education has entered the national education development plan. In September 2017, the Ministry of education of China issued the "guiding outline of comprehensive practical activities for primary and secondary schools" in the form of teaching materials. The release of the textbook means that the Ministry of education of China defines STEAM education in schools as comprehensive practical activity courses. In the future, it will be an important development trend of China's education to comprehensively carry out comprehensive practical activities courses on campus.

\section{DEMAND SIDE ANALYSIS}

\subsection{Consumption Upgrading Promotes the Change of STEAM Quality Education Concept}

The upgrading of consumption promotes the change of residents' educational concept and drives the continuous growth of the scale of education and training market. According to the data, as shown in Figure 1, China's per capita disposable income has increased from $20,167 \mathrm{CNY}$ in 2014 to $28,228 \mathrm{CNY}$, and the growth of per capita disposable income marks a significant improvement in the overall consumption level of Chinese residents. In the composition of per capita consumption expenditure, the per capita expenditure on education, culture and entertainment of Chinese residents is also gradually increasing, with the amount increasing from 1,536 CNY in 2014 to 2,226 CNY in 2018, reflecting the shift of residents' consumption concept. The growth of per capita disposable income of residents and the increasing expenditure on education investment provide strong support for the growth of education and training market scale, and also provide driving force for the development of STEAM education industry.

Data source: National Bureau of Statistics

China's emerging middle class, that is, the population with private investable assets between 50,000 and 500,000 US dollars, is rapidly rising. The scale of the middle class is constantly expanding, and the residents' ability to bear education investment is higher. See Figure 2 for details. In addition, the main body of parents of Chinese primary and secondary school students has gradually turned to the post-80s and post-90s groups, and the structure of parents tends to be younger. Compared with the traditional parents, the post-80s and post-90s parents have a more open consumption concept and pay more attention to the cultivation of children's comprehensive quality. Their education concept has changed from traditional examination oriented education to quality-oriented education, which can also be proved in Figure 3

Data source: 2018 Weibo Report on the Trends of Family Consumption in Education for Children

Data source: 2018 Survey Report on Burden Alleviation for Primary/Secondary School Students 


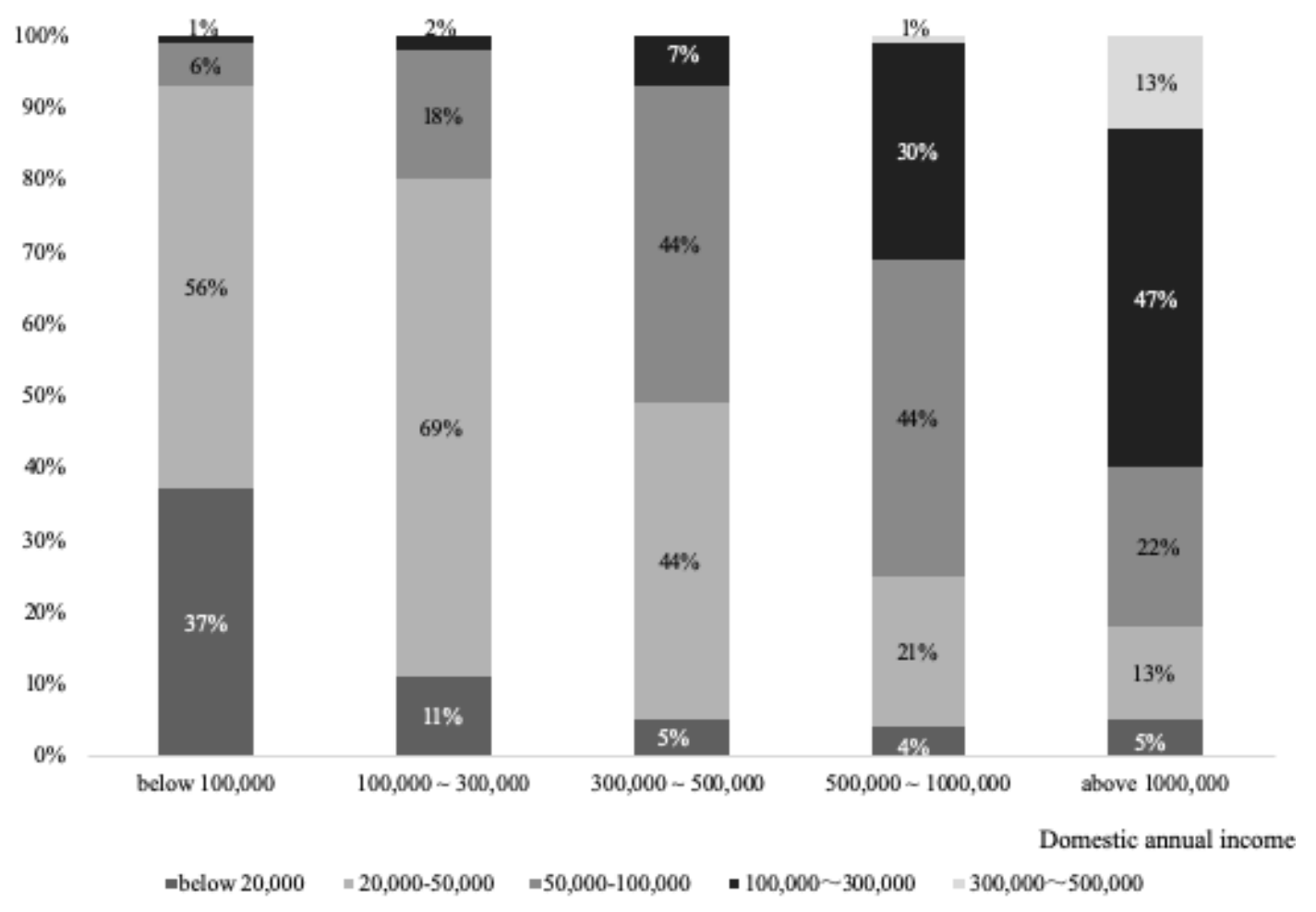

Figure 2: Composition of different family income levels and different levels of childrearing expenditure (CNY)

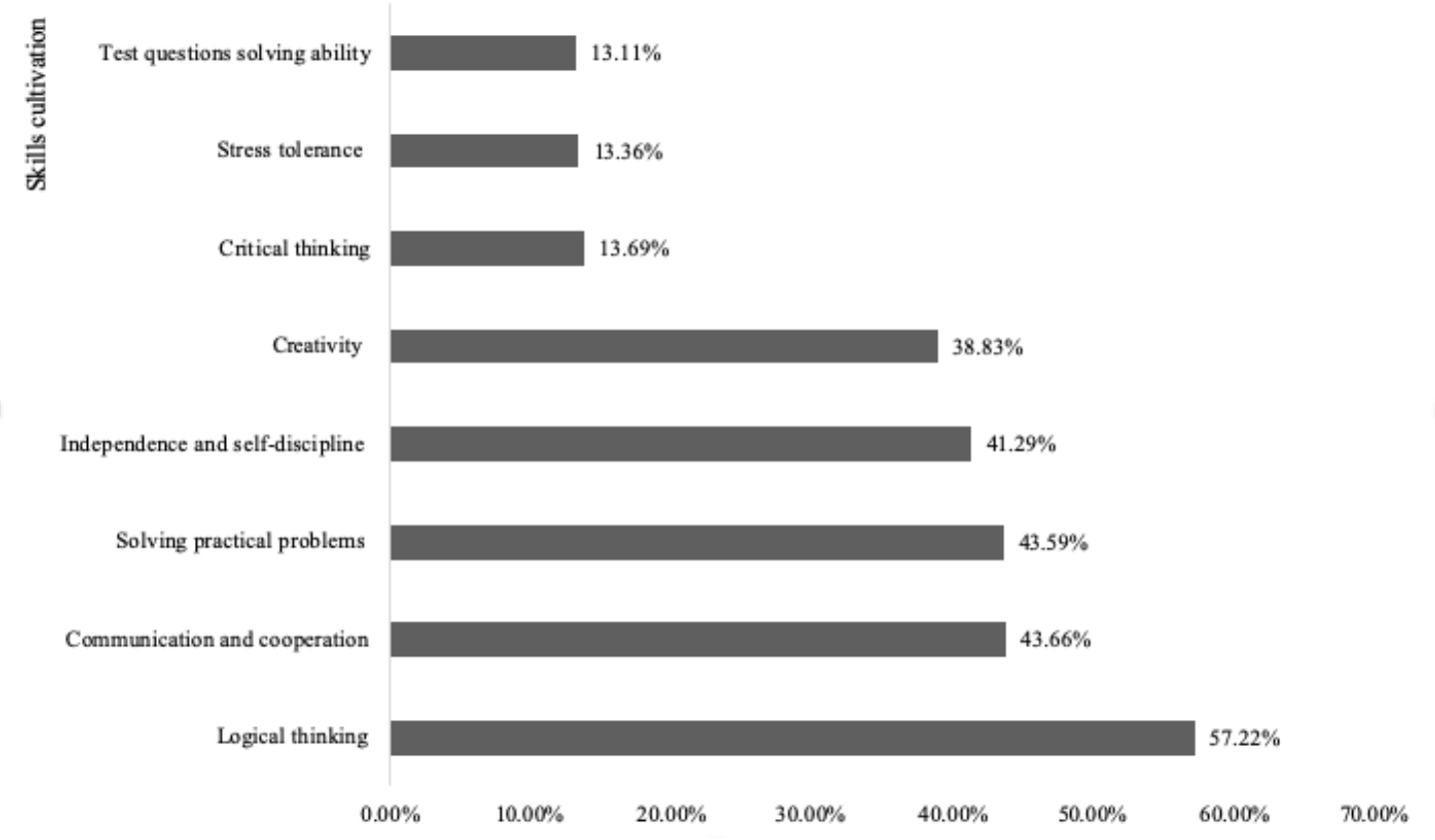

Figure 3: Parents value training children's logical thinking ability the most 


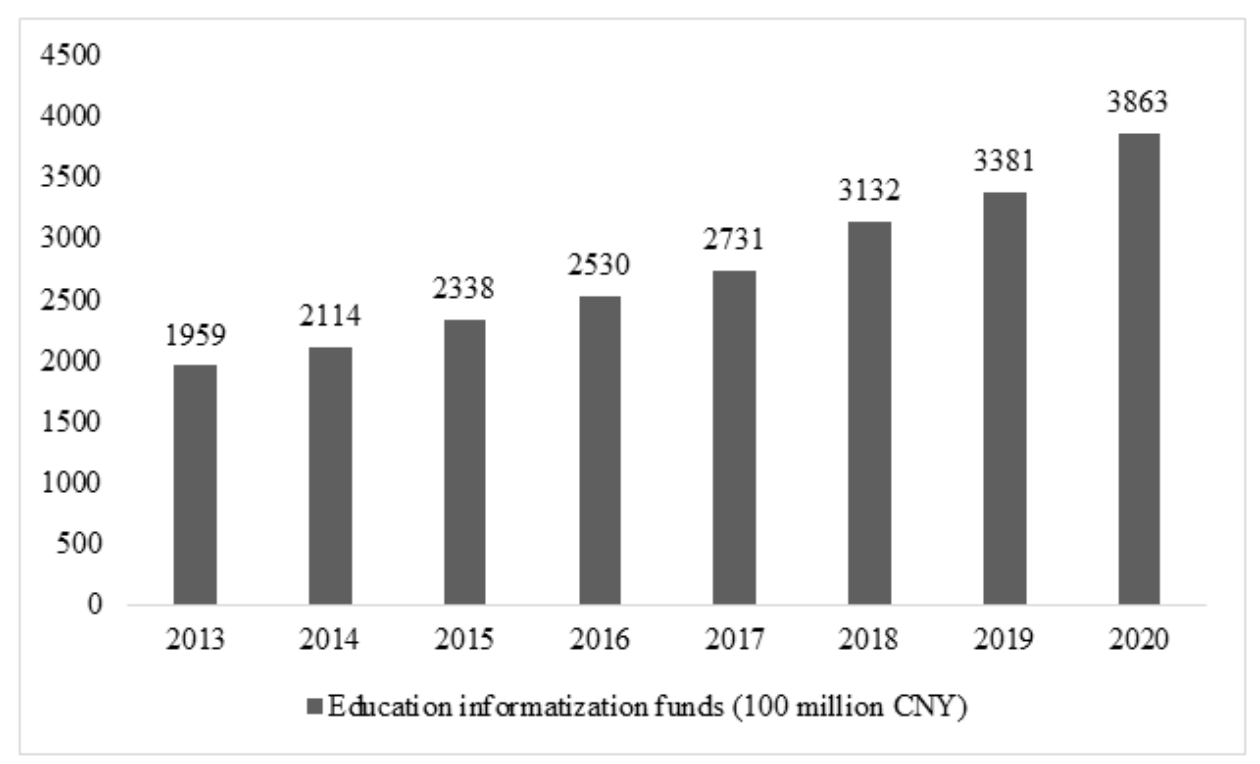

Figure 4: China's financial allocation for education informatization in 2013-2020

\subsection{The Development of Science and Technology Promotes the Demand for Relevant Talents}

With the great progress of artificial intelligence, Internet of things and other science and technology, human society is gradually moving from the information age to the intelligent era. The advent of the intelligent era promotes the social demand for compound talents with comprehensive discipline application ability. As of 2018, there are more than 5 million artificial intelligence talents in China, and the supply and demand of talents in the field of artificial intelligence is seriously unbalanced. In terms of the specific salary and treatment of artificial intelligence related posts, the starting salary level of China's graduate students in 2018 was 6,824 CNY, while the average monthly salary of fresh graduates in artificial intelligence related posts was close to $10,000 \mathrm{CNY}$, which attracted more talents to invest in the field of artificial intelligence. STEAM education emphasizes the comprehensive exertion and creativity of disciplines, advocates the integration of subject knowledge in different fields, and meets the teaching requirements of interdisciplinary subjects such as artificial intelligence. Moreover, its subdivision domain programming education and robot education are important components of the teaching foundation of artificial intelligence discipline. A large number of market talent gaps and ideal salary treatment are paid for STEAM education The exhibition provides sufficient potential customers.

At the same time, the important development prospects of artificial intelligence and other technologies have prompted the Chinese government to gradually attach importance to the cultivation of talents in the field of artificial intelligence, and the government has continuously promulgated policies to promote the transition of examination oriented education to quality education. As of July 2018 , nearly $20 \mathrm{AI}$ colleges and research institutes have been established in Chinese universities, and python, a popular AI programming language in recent years, has been included in the college entrance examination of Zhejiang Province. In addition, mature informatization construction can create a good experience environment for STEAM education. Since 2012, the Chinese government has continuously invested a lot of money to promote the application of information-based education technology. In 2020, China's financial investment in education informatization will reach 386.3 billion yuan (see Figure 4 for details). The government's long-term investment in education informatization becomes a strong supporter for the stable development of STEAM education in China.

Source: Ministry of Education

\subsection{Technology Application Enriches STEAM Teaching Content and Improves Students' Experience}

2.3.1 UAV. In 2018, UAVs designed for educational programming are becoming more and more popular. Primary and secondary schools in some first tier cities begin to explore introducing UAVs into STEAM teaching courses and offering UAV programming courses. Different from the traditional programming education, UAV programming course has the advantages of strong interest, combination of software and hardware and rich content. In recent years, the new UAV with safety cover has developed the functions of "one key landing", "automatic hovering", etc., which can largely avoid the danger of classroom teaching.

2.3.2 3D Printing Technology. 3D printing technology is usually used in STEAM education in two forms: (1) professional 3D design software, mainly for middle school students and college students. In the process of learning application professional 3D design software, students carry out exploratory design according to different open design requirements and use 3D printer to materialize the design model; (2) simple 3D design software is mainly for primary school 


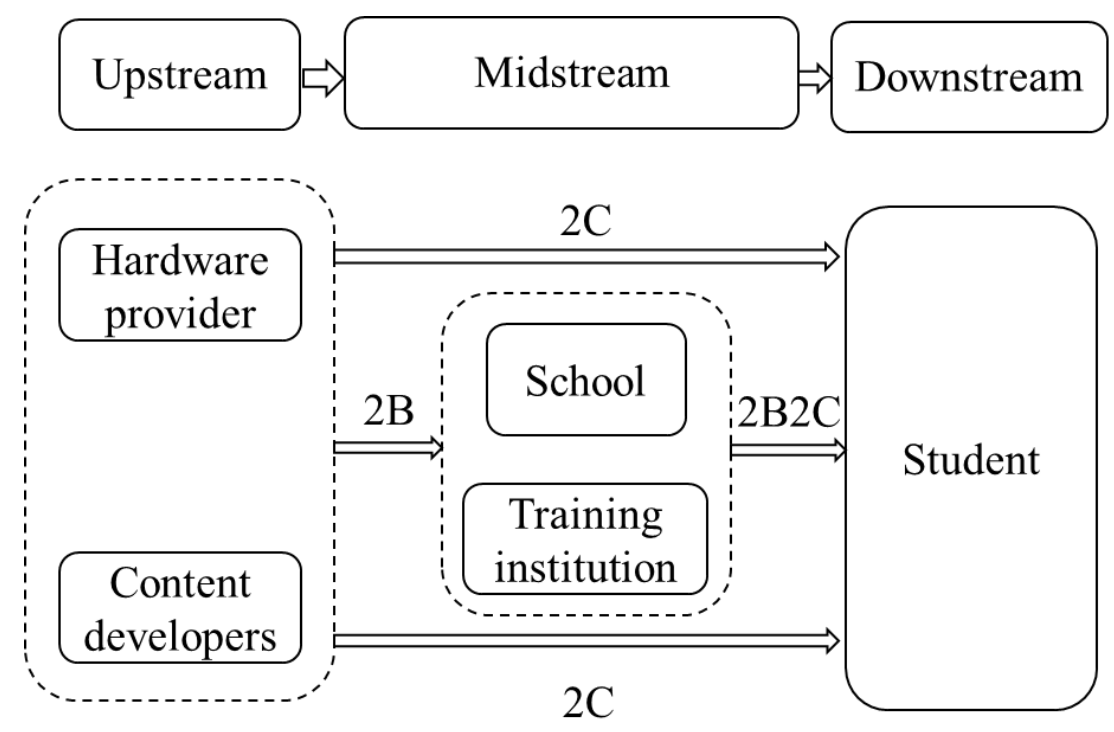

Figure 5: STEAM education industry chain in China

students. Simple 3D design can cooperate with 3D scanner to carry out rapid 3D design, which enables students to quickly obtain the basic 3D data of creative works and print out after secondary design. The early $3 \mathrm{D}$ printing technology process is complex and the precision is poor. The current $3 \mathrm{D}$ printing technology tends to be simple and accurate, and gradually solves the problems of primary and secondary school students' lack of interest due to technical operation difficulties.

2.3.3 AR. The characteristics of AR technology such as multimedia dynamic presentation, virtual reality combination, 3D rendering and interaction can stimulate students' enthusiasm for independent exploration and improve their learning efficiency. In addition, the traditional teaching carrier can use AR technology to make the turgid knowledge present in a more straightforward way, solve the common complex and boring problems in interdisciplinary learning, and improve students' comprehensive quality.

\section{SUPPLY SIDE ANALYSIS}

\subsection{Industrial Chain Analysis}

As shown in Figure 5, the industrial chain of China's STEAM education industry can be divided into three parts: upstream market participants include hardware suppliers and content developers; the participants in the middle reaches of the industrial chain are education and training institutions or education platforms, which provide relevant teaching for downstream customers through independent research and development or introduction of STEAM education courses; and the downstream links of the industrial chain are mainly STEAM User groups of education.

The downstream industry chain of STEAM education industry in China is mainly customer audience, usually young people aged 4-18. The customer audience of STEAM education can be stratified according to their age. At present, more than $80 \%$ of the customers of STEAM education in China are primary school students, and the rest of the market is mainly concentrated in middle school students. The learning habits and needs of the audience at different levels are different, mainly as follows:

(1) Preschool children

The focus of STEAM education course for preschool children is to stimulate children's cognitive interest and inquiry desire, mainly with LEGO toy splicing and VR experience.

(2) Primary school students

As the main force of STEAM education market, primary school students' education and training focus on cultivating their interdisciplinary comprehensive application ability, logical thinking and practical ability. Taking the campus STEAM education case "I and plants" as an example, this case requires teachers to guide students to start with observing the shape, color and size of plant seeds, analyze the differences between different plant seed structures, and then give students to explore the conditions required for seed germination, observe and record the growth and change of seeds, and explore the role of plant roots, stems and leaves. After the completion of plant cultivation, the teacher will lead the students to create seed paintings, which will be completed by several student groups. In addition, the school can focus on seed germination, let students design experimental observation, comparison, cognitive basic conditions of seed germination, and realize the cross teaching of biology, aesthetics and other disciplines.

(3) Middle school students

Compared with other groups, middle school students pay more attention to the skills improvement brought by programming education and robot education. The main reason is that the Chinese government has adopted STEAM Education has gradually been incorporated into the formal syllabus. Since 2018, information technology (including programming language learning) has become one of the selected subjects for college entrance examination in Zhejiang Province. In addition, many universities in China have recognized robot competition awards in their independent enrollment, 
and a few junior and senior high schools have begun to recruit students with science and technology expertise;

(4) College Students

The subjective consciousness of college students is strong, and they prefer the practical and experiential teaching. With the advent of the Internet information age, the employment market has a strong demand for comprehensive talents with excellent programming ability. STEAM programming education has gradually attracted the attention of college students.

\subsection{Lack of Teachers and Serious Homogenization of Curriculum}

Compared with the mature STEAM education market in developed countries, China's STEAM education has many problems in terms of teachers, curriculum system and social cognition.

3.2.1 Curriculum System. China's STEAM education industry has not yet formed a mature curriculum system. Large training institutions usually adopt the mode of "learning from the mature teaching system of developed countries + independent research and development of institutional teams", that is, to improve and develop curriculum content with Chinese characteristics on the basis of overseas teaching system. However, most of STEAM education and training institutions lack of independent research and development strength, resulting in serious homogenization and poor applicability of industry teaching curriculum content, which directly leads to the lack of user experience, and then challenges the concept of STEAM education, which is not conducive to the good development of the industry. In addition, because the Chinese government has not clearly planned the STEAM education related syllabus, the industry lacks a unified teaching standard, and training institutions arrange teaching according to their own plans, the final teaching effect is quite different, and consumers are prone to feel distrust.

3.2.2 Teachers. There is a serious shortage of teachers in STEAM education in China, and a complete teacher training system has not yet been formed. STEAM education focuses on the integration of knowledge of different disciplines, which is a form of quality education that emphasizes the cultivation of students' scientific and creative ability. Therefore, STEAM education requires teachers to have broad knowledge base, proficient information technology operation and thorough learning and understanding ability, and requires high comprehensive quality of teachers. In 2018, there are more than 3 million teachers in China's STEAM education industry. From the perspective of the employment market, the reasons for the huge talent gap can be divided into two aspects: 1) the traditional normal teachers are difficult to engage in the teaching of relevant programming, machine human and other emerging technology courses, and can not meet the higher threshold requirements of the industry; 2) the average salary of programming posts is much higher than that of ordinary teachers Teachers lead to serious brain drain. From the perspective of teacher training system, most of the industry teachers have professional background in computer science, engineering and other related sciences, generally lack of teaching experience, and it is difficult to strictly control the teaching quality, which directly affects the learning effect of students. The shortage of teachers and the lack of perfect teacher training system have restricted the development scale of STEAM education industry in China and seriously hindered the further development of the industry.

\subsection{The Course Price is Expensive and the Promotion of Public Schools is Limited}

The shortage of teachers and high teaching cost are the important reasons for the high price of STEAM education courses. Different from the traditional teaching methods, STEAM education needs to be equipped with complete software and hardware facilities to train students' practical ability. At present, China's STEAM education and training institutions lack sufficient bargaining power for hardware suppliers and content suppliers in the upstream of the industrial chain, and have a high dependence on foreign brands with high product prices, which leads to STEAM in the market The price of education courses is generally high, and most working families are difficult to support students to accept STEAM education for a long time. Take the summer STEAM Education Summer Camp as an example, it mainly provides 5 days and 40 class hours for primary and secondary school students, and the course fee is more than 7,000 CNY. At the same time, STEAM education concept does not pay attention to the examination link, which is different from the traditional Chinese family's cognitive concept of determining the teaching quality by examination results, which is difficult to persuade parents to pay high course fees for students. Therefore, the expensive curriculum fees and the lack of immediate teaching effect are the important factors that hinder parents from choosing STEAM education.

At the same time, the expensive courses and the lack of enough teaching talents are the main problems in promoting STEAM education on campus. The mode of "school + off campus education and training institutions" is used to promote STEAM education on campus, that is, the school cooperates with large STEAM education and training institutions, and the education and training institutions provide mature teaching system, perfect software and hardware facilities and high-quality teachers. Although the Chinese government has continuously issued favorable policies to promote the quality education reform and encourage STEAM education to enter the campus, only some schools in the first tier cities meet the relevant conditions to introduce STEAM education. Most of the schools are limited by funds, scale and examination pressure, which makes it difficult to promote STEAM education in a large scale, which is not conducive to the overall development of STEAM education.

\section{ANALYSIS ON THE FUTURE DEVELOPMENT TREND}

\subsection{The Degree of Social Participation is Gradually Improved, and STEAM Teaching Scenes are Constantly Enriched}

Learning from the mature experience of STEAM education market in developed countries, the teaching mode of overseas STEAM education is mainly project-based learning (PBL), that is, a teaching and learning method that takes students as the center to design and implement projects. PBL teaching mode requires students to choose, 
plan and put forward the idea of a project within the specified time, and solve practical problems by trying various forms. Compared with the traditional teaching mode, PBL promotes students to master multi-disciplinary knowledge more efficiently by combining practice with reality, which can effectively exercise students' divergent thinking and multi angle interpretation ability.

Through interviews with experts with rich experience, the teaching mode of STEAM education industry in China is not mature, and PBL teaching mode is one of the important directions of future development. Project based learning needs more application scenarios to meet the teaching needs. Overseas STEAM education focuses on three scenarios: family, school and society. In the three scenarios, schools pay attention to the training of students' comprehensive ability, families are more inclined to cultivate students' life values, and society provides a more real practice platform for cultivating students with comprehensive ability.

As the main part of society, community and enterprise play an important role in STEAM education system. Government departments, communities and enterprises cooperate with each other to promote the cultivation of students' comprehensive application ability of disciplines. With the implementation of relevant policies of the Chinese government, the community will play a more important role in the STEAM education system for primary and preschool children. In addition, the enterprise is one of the important application scenarios of STEAM education, and the participation of social enterprises in developed countries is high. Bill Gates and other world-famous entrepreneurs have successively publicized STEAM education. A large number of well-known enterprises in Europe and America have provided STEAM teaching practice platform for students to experience the real operating environment. At present, China's social enterprises mostly stay in playing the role of "public opinion", and lack of linkage with communities, families and schools. In the future, with the further maturity of China's STEAM education market, the relationship among families, schools and society will become more closely, and more abundant teaching scenes will be derived.

\subsection{The Mainstream Teaching Curriculum Mode is Developing Towards 2B2C}

$2 \mathrm{~B} 2 \mathrm{C}$ model is expected to help enterprises realize the realization of brand value with low cost, which will gradually become the mainstream business model of the industry. The business models of STEAM education enterprises can be generally divided into $2 \mathrm{~B}$ mode, $2 \mathrm{C}$ mode and $2 \mathrm{~B} 2 \mathrm{C}$ mode. In the early stage of China's STEAM education market, $2 \mathrm{C}$ mode was the main business model and $2 \mathrm{~B}$ mode was the auxiliary mode. In 2016, the market share of direct sales to end consumers exceeded $60 \%$ of the total. Under the background of the continuous promotion of quality education reform by the Chinese government, campus education has become the main teaching scene of STEAM education. $2 \mathrm{~B}$ mode is gradually replacing $2 \mathrm{C}$ mode. The business model of STEAM education industry in China has evolved into 2B mode as the main mode and $2 \mathrm{C}$ mode as the auxiliary mode.

With the further maturity of the industry, a few STEAM education enterprises have the strength to integrate $2 \mathrm{~B}$ and $2 \mathrm{C}$ business models, namely 2B2C business model. Take Shenzhen UBTECH as an example: for the C-end market, UBTECH adopts the online and offline sales mode, that is, more than 7,000 direct sales outlets are set up offline, and nearly 500 Apple stores around the world are settled. Online development of e-commerce channels such as JD, TMALL and Amazon has established a comprehensive marketing network. For the b-end market, Uber has reached teaching cooperation with many primary and secondary schools around the world, including the cooperation between UBTECH and Shenzhen Overseas Chinese city middle school to build a robot laboratory, providing professional services in teaching hardware, technology, teaching courses, teachers, etc. In April 2017, UBTECH signed a strategic cooperation with Kunming Municipal People's government to establish robot electric classrooms in hundreds of primary and secondary schools in Kunming. UBTECH chooses to lay out both B-end and C-end markets at the same time, use B-end market to form brand effect, drive C-end market's consumption enthusiasm, improve product research and development with the help of C-end market user experience, and feed back to B-end market to form a good marketing ecology.

\section{CONCLUSION}

\subsection{Summary}

Science and technology promote talent demand and promote government education reform. Along with the great progress of AI, Internet of things and other science and technology, human society is gradually moving from the information age to the intelligent era. The advent of the intelligent era boosts the social demand for compound talents with comprehensive discipline application ability. At the same time, the important development prospects of artificial intelligence and other technologies have prompted the Chinese government to gradually attach importance to the cultivation of talents in the field of artificial intelligence, and the government has continuously promulgated policies to promote the transition of examination oriented education to quality education.

Technology application enriches teaching content and improves user experience. The innovation and development of STEAM education needs mature technical support. With the continuous maturity of 3D printing, UAV, artificial intelligence and other technologies, STEAM education products show a trend of diversification. The rapid development of VR and AR technology provides more development direction for STEAM education. The teaching carrier of STEAM education adds virtual and augmented reality technology, UAV and other technology applications, which greatly enriches the teaching content and improves the user experience.

The degree of social participation is improved and STEAM teaching scene is rich. Enterprises and communities are an important part of society. For STEAM education, Chinese enterprises mostly stay in playing the role of "public opinion", and lack of linkage with communities, families and schools. In the future, with the further maturity of China's STEAM education market, the relationship among families, schools and society will be more closely, and more abundant teaching scenes will be derived. 


\subsection{Outlook}

Due to the limitation of data and data in the field of education, the author does not further analyze the data and data in the field of education.

\section{REFERENCES}

[1] Yilip Kim, Namje Park. The Effect of STEAM Education on Elementary School Student's Creativity Improvement[M]// Computer Applications for Security, Control and System Engineering. 2012.

[2] Park N, Ko Y. Computer Education's Teaching-Learning Methods Using Educational Programming Language Based on STEAM Education.[M]// Network and Parallel Computing. 2012.

[3] Peppler, Kylie. STEAM-Powered Computing Education: Using E-Textiles to Integrate the Arts and STEM[J]. Computer, 46(9):38-43.
[4] Sanders M E. STEM, STEM Education, STEMmania[J]. 2008, 68(4):20-26

[5] Bybee, Rodger W. Advancing STEM Education: A 2020 Vision[J]. Technology \& Engineering Teacher, 2010, 70(1):30-35.

[6] HOEG, DARREN G, BENCZE, JOHN LAWRENCE. Values Underpinning STEM Education in the USA: An Analysis of the Next Generation Science Standards[J]. Science Education, 101(2):278-301.

[7] Hyunju Park, Soo-Yong Byun, Jaeho Sim. Teachers' Perceptions and Practices of STEAM Education in South Korea[J]. Eurasia Journal of Mathematics Science \& Technology Education, 12(7).

[8] B.-H. Kim, J. Kim. Development and Validation of Evaluation Indicators for Teaching Competency in STEAM Education in Korea[J]. Eurasia Journal of Mathematics Science \& Technology Education, 12(7).

[9] Wang Juan, Wu Yonghe. The Reflection and Innovation Path of STEAM Education Application in the Era of "Internet+"[J]. Journal of Distance Education, 2016.

[10] Li Xiaotao, Gao Haiyan, Zou Jiaren. Changes of STEAM Education to Maker Education under the Background of "Internet+":From Project-based Learning to Innovation Ability Cultivation[J]. Journal of Distance Education, 2016. 